\title{
Penerapan Reproducible Research pada RStudio dengan Bahasa R dan Paket Knitr
}

\author{
Weksi Budiaji \\ Jurusan Agribisnis, Fakultas Pertanian \\ Universitas Sultan Ageng Tirtayasa \\ Serang, Banten, Indonesia \\ budiaji@untirta.ac.id
}

\begin{abstract}
Abstrak-Reproducible Research (RR) atau penelitian yang hasilnya dapat diulang sangat penting dalam sebuah penelitian karena dengan demikian peneliti lain akan dapat menjalankan ulang atau mengembangkan hasil penelitian sebelumnya dengan data dan kode yang telah tersedia. RStudio sebagai integrated development environment (IDE) software R dan paket Knitr menawarkan kemudahan untuk RR karena data dan kode dapat tersedia dengan mudah. Langkah pembuatan RR adalah pembuatan file .rmd, penyesuaian meta data, penulisan teks dan kode (cbunk), dan rendering. Penerapan teks-kode, teks-tabel, dan teks-gambar pada sebuah contoh kasus artikel dengan RStudio, software $\mathrm{R}$ dan paket Knitr memberikan keuntungan yaitu penyesuaian hasil dan pengecekan yang lebih menghemat waktu jika terjadi perubahan data, cross reference yang mudah pada tabel dan gambar, dan kemudahan peneliti lain memanfaatkan data dan kode yang telah tersedia. Pengadopsian reproducible research (data dan kode tersedia) menjadi penting bagi seorang peneliti agar kontribusi terhadap keilmuan lebih efektif.
\end{abstract}

Kata kunci: Reproducible Research; penelitian; kode; data

\section{Pendahuluan}

Reproducible research (RR) atau penelitian yang hasilnya dapat diulang merupakan elemen yang sangat penting dalam sebuah penelitian. Hasil penelitian dapat dikatakan reproducible jika peneliti lain dapat menghasilkan temuan yang sama pada data yang berbeda tetapi dengan prosedur yang sama [1]. RR sangat penting pada penelitian kuantitatif maupun kualitatif [2], bahkan perubahan kebijakan tentang keharusan RR pada jurnal Science membuat $95 \%$ artikel yang diterbikan dapat diproduksi ulang (reproducible) [3]. Pada penelitian kuantitatif yang berdasarkan percobaan/survei, RR berarti bahwa peneliti lain yang tidak terlibat dalam penelitian dapat meneliti ulang dengan percobaannya atau dengan samplingnya dan memvalidasi hasil temuannya yang sebanding dengan hasil penelitian terdahulu [1].

Standar RR di statistika komputasi adalah data dan kode untuk menganalisis data tersedia bagi peneliti lain [4], sehingga tools statistik yang berdasarkan menu akan sulit digunakan sebagai pendukung $\mathrm{RR}$ karena menu biasanya tidak didukung dengan kode. Beberapa tools yang dapat digunakan untuk RR antara lain VisTralis, Sumatra, dan CDE [5]. Khusus software R, RR dapat menggunakan Sweave [6] atau Knitr [7] yang keduanya dapat menampilkan hasil yang baik [8]. MATLAB dan Python yang menggunakan command line/kode juga dapat digunakan untuk RR, tetapi software/bahasa R menjadi tools untuk RR yang paling mudah karena didukung oleh komunitas yang kuat dan kemunculan RStudio sebagai integrated development environment (IDE) yang bebas (free) dan handal untuk bahasa R.

Software $\mathrm{R}$ adalah bahasa dan software yang dapat diperoleh dengan bebas untuk statistika komputasi dan grafik yang dikembangkan oleh $\mathrm{R}$ Core Team [9]. Salah satu kekuatan dari $\mathrm{R}$ adalah dukungan komunitas dalam bentuk paket-paket yang dapat diunduh dengan bebas dari cran- $R$. Ada banyak pilihan editor bahasa $\mathrm{R}$ untuk mempermudah penggunaan $\mathrm{R}$, tetapi yang paling sering digunakan adalah RStudio karena selain berfungsi sebagai editor, RStudio juga merupakan IDE untuk bahasa R. RR pada RStudio dapat menggunakan Sweave yang berdasarkan pada bahasa TeX atau Knitr yang menggunakan bahasa rmarkdown.

Artikel ini menggunakan Knitr untuk menghasilkan contoh RR pada sebuah kasus data riil. Bab kedua menjelaskan metode/cara Knitr dengan baris-baris perintah/kode dalam RStudio yang dapat memunculkan hasil sesuai dengan standar RR. Bab ketiga menganalisis dan mendiskusikan data riil, sedangkan bab terakhir kesimpulan.

\section{Metode}

Paket Knitr dibuat untuk memudahkan penggabungan teks dan kode $\mathrm{R}$ pada sebuah laporan agar jika terjadi perubahan pada data, peneliti tidak perlu lagi mengganti teks atau kode yang telah ditulis [10]. Karakter ini yang membuat RStudio dan Knitr sangat cocok untuk RR. Knitr dapat dipasang setelah sofware R dan RStudio terpasang dengan benar pada komputer yaitu dengan mengetikkan install.packages(Knitr). File baru yang harus dibuat untuk RR pada RStudio adalah $\mathrm{R}$ markdown. Ekstensi dari file ini berupa .rmd. Langkahlangkah untuk membuat sebuah file .rmd agar dapat digunakan untuk RR adalah 
a. Buka RStudio dan pilih File $>$ New File $>$ R Markdown untuk membuat file berekstensi .rmd.

b. Tulis meta data pada bagian atas (front-matter) dari file .rmd.

Meta data sangat penting karena berfungsi untuk mengatur teks yang akan dihasilkan misalnya judul, nama penulis, ukuran huruf, hasil teks (pdf, word, atau html) dan lain sebagainya. Bagian meta data berada pada blok paling atas dan diawali/diakhiri dengan baris kode ---. Meta data artikel ini dapat dilihat pada Gambar 1.

3. Tulis teks di bawah meta data.

Bagian teks berisi tulisan teks yang berada di bawah meta data. Teks yang dibuat dapat seperti teks pada MS Word, misalnya menebalkan atau memiringkan teks. Persamaan juga dapat ditulis, baik tersisip pada baris teks atau satu blok persamaan tersendiri. Jika sitasi disisipkan pada teks, sitasi tersebut akan muncul otomatis pada bagian akhir (daftar pustaka). Gambar 2 memperlihatkan teks Pendahuluan dari artikel ini.

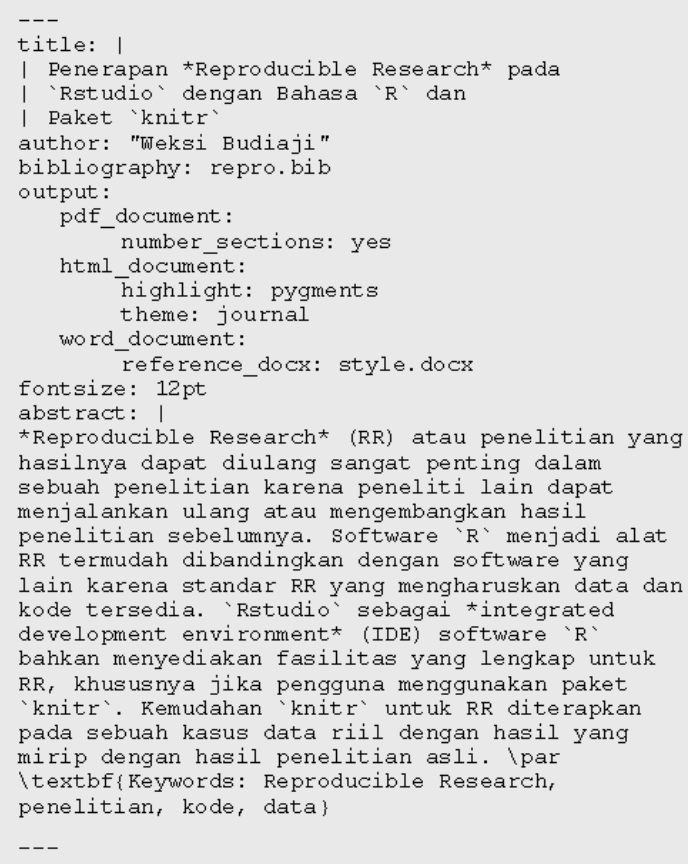

\section{Gambar 1. Meta data artikel}

4. Tulis kode bahasa $\mathrm{R}$ pada bagian kode (chunk).

Bagian kode/chunk berisi kode/bahasa R. Bagian kode dapat ditulis inline/tersisip pada teks dengan menggunakan kode 'r ekspresi', misalnya angka 2 yang tertulis dalam kalimat ini menggunakan kode 'r 1+1' yang disisipkan (bukan menekan angka 2 di keyboard). Chunk dengan beberapa baris kode (blok kode) sebagai berikut:

\section{$\cdots\{r\}$ \\ $1+1$}

Saat blok kode digunakan, latar belakang RStudio akan berubah (highlight). Jika tidak ada highlight di latar belakang, blok kode akan dianggap teks biasa sehingga blok kode tidak dijalankan oleh
R. Diantara dua kurung kurawal $(\{\ldots\})$ dapat dituliskan pilihan-pilihan untuk mengatur hasil yang diinginkan, misalnya echo untuk menampilkan/ menyembunyikan kode R, fig . cap untuk memberi judul pada gambar yang dihasilkan, dan sebagainya. Perlu diperhatikan bahwa kedua tanda kurung tersebut harus dalam satu baris kode (jangan menekan enter) agar kode blok dapat bekerja saat dijalankan.

5. Jalankan file .rmd (rendering)

File .rmd dapat diubah menjadi format lain dengan memilih Knit HTML, Knit PDF, atau Knit Word. Di Komputer harus terpasang software pemroses latex dokumen seperti MiKteX, TeXLive, atau MacTeX jika hasil yang diinginkan berupa pdf, atau cara lain dengan memasang paket tinytex di RStudio yaitu dengan menjalankan/menuliskan perintah install.packages (tinytex).

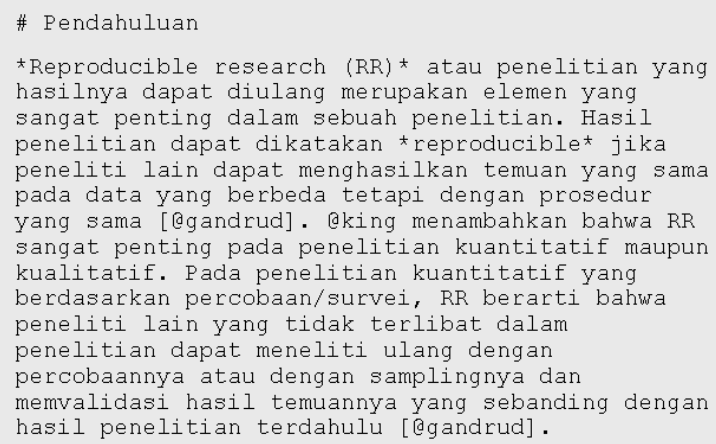

\section{Gambar 2. Teks di luar meta data}

Langkah-langkah pembuatan file untuk RR dapat diterapkan sejak dari awal penelitian, sehingga penyesuaian teks dan kode lebih mempersingkat waktu. Contoh kasus RR yang didiskusikan pada bagian berikutnya adalah kasus riil dari pemetaan komoditas sayuran di Kota Serang, Provinsi Banten yang menggunakan indikator produksi dan sosial-ekonomi [11]. Pembahasan contoh kasus ini mirip dengan artikel asli (bukan menerjemahkan) dengan menitikberatkan pada penggunaan kode $\mathrm{R}$ pada paket Knitr. Data dan kode R berekstensi .rmd tersedia dan dapat diunduh di laman OSF (Open Science Framework) (https://osf.io/ds74a/) penulis untuk memenuhi standar RR pada statistika komputasi [4], sehingga peneliti lain dapat memproduksi ulang file .rmd dan mendapatkan hasil yang sama dengan artikel ini.

\section{Hasil dan Diskusi}

Data set pada kasus pemetaan sayuran di Kota Serang [11] terdiri atas dua sumber yaitu data sosial ekonomi petani hasil survei dari 33 responden di enam kecamatan (Cipocok Jaya, Curug, Kasemen, Serang, Taktakan, dan Walantaka) dan data produksi sayuran yang berasal dari data sekunder [12]. Bab ini mengambil sebagian pembahasan dari artikel asli untuk diproduksi ulang yang menitikberatkan pada bagian (1) teks dan kode, (2) teks dan tabel, dan (3) teks dan gambar agar artikel ini menjadi contoh artikel RR yang lengkap. 


\section{a. Teks dan kode}

Paragraf pertama dari Respondent characteristics dapat dijadikan sebagai pembahasan untuk teks dan kode. Sebelum menuliskan teks dan kode yang berdasarkan pada suatu data, load data (data berupa file kuisioner. txt berada pada folder C:/) dijalankan terlebih dahulu agar data terbaca oleh sistem dan variabel-variabel didefinisikan untuk mempermudah penulisan kode inline. Variabel survei adalah data yang telah tersimpan di sistem, sedangkan variabel-variabel lain, misalnya responden, laki, usia 40, dan seterusnya, untuk membantu penulisan kode inline. Variabel-variabel yang akan digunakan dalam artikel dapat disimpan terlebih dahulu tanpa menampilkan pada artikel yaitu dengan cara menambahkan echo $=$ FALSE. Penulisan di RStudio dapat dilakukan seperti pada Gambar 3, kemudian satu paragraf yang berisi teks dan kode dapat ditulis seperti pada Gambar 4. Hasil dari teks dan kode terlihat pada Gambar 5.

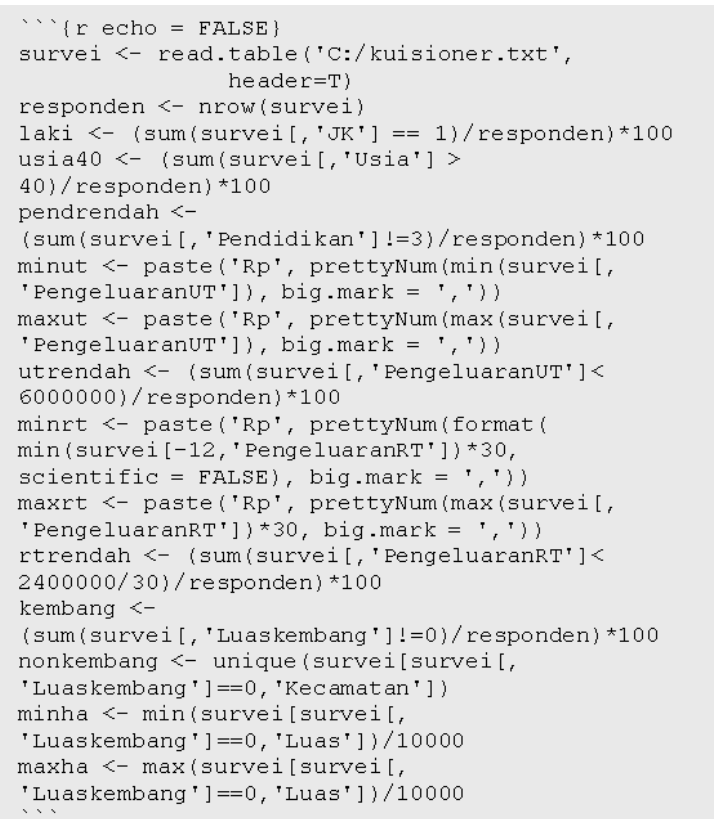

\section{Gambar 3. Penyimpanan variable dengan echo $=$ FALSE}

Ada ' $r$ responden' petani sayuran yang terlibat dalam survei. ' $r$ round (laki, 0 ) ' $\backslash 8$ dari responden berjenis kelamin laki-laki. Usia responden paling muda adalah ' $r$ min(survei[,'Usia'])' tahun dan yang paling tua adalah ' $r$ max (survei [, 'Usia']) tahun dan sebanyak ' $r$ round (usia40,0) ' $\backslash 8$ usianya diatas 40 tahun. Mayoritas respoden memiliki latar belakang pendidikan yang rendah, sekitar ' $r$ round (pendrendah, 0 ) ' $\backslash 8$ adalah

lulusan sekolah dasar dan sekolah menengah pertama. Pengeluaran usaha tani responden mempunyai variasi yang tinggi dari ' $r$ minut hingga ' $r$ maxut' sesuai dengan luas lahan sistem usaha tani responden. ' $r$ round (utrendah, 0 ) ' 18 responden mempunyai pengeluaran untuk sistem usaha tani (SUT) kurang dari Rp 6.000 .000$. Pengeluaran rumah tangga responden per bulan bervariasi dari ' $r$ minrt' hingga ' $r$ maxrt' dengan sekitar ' $r$ round (rtrendah, 0$)^{\prime} \backslash 8$ responden mempunyai pengeluaran rumah tangga per bulan kurang dari Rp 2.400.000. Ada $r$ round (kembang, 0 ) ' $\backslash 8$ responden berkeinginan untuk mengembangkan SUT, dengan ' $r 100$ round (kembang, 0 ) ' $\backslash 8$ yang tidak berkeingingan mengembangkan SUT berada di Kecamatan ' $r$ nonkembang' karena mempunyai akses ke SUT sekarang hanya 'r minha' sampai dengan 'r maxha ha.

\section{Gambar 4. Paragraf dengan teks dan kode}

Jika dibandingkan teks dan kode antara RStudio dan hasil akhir yaitu Gambar 4 dan Gambar 5, terdapat perbedaan pada mayoritas angka/bilangan yang dihasilkan pada hasil akhir. Angka yang tercetak pada hasil akhir merupakan hasil olahan dari kode $\mathrm{R}$ inline. Keuntungan yang diperoleh adalah jika terjadi perubahan pada data, misalnya salah input sehingga harus dijalankan/ dianalisis ulang, penggunaan teks dan kode ini sangat mengungtungkan karena hanya memerlukan pengecekan yang lebih minimal (lebih menghemat waktu) dibandingkan tanpa kode inline. Keuntungan lain adalah peneliti yang ingin menggunakan kode juga lebih mudah, karena kode tersedia sehingga Reproducible Research terjamin.

Ada 33 petani sayuran yang terlibat dalam survei. 948 dari responden berjenis kelamin laki-laki. Usia responden paling muda adalah 25 tahun dan yang paling tua adalah 65 tahun dan sebanyak 798 usianya diatas 40 tahun. Mayoritas respoden memiliki latar belakang pendidikan yang rendah, sekitar 918 adalah lulusan sekolah dasar dan sekolah menengah pertama. Pengeluaran usaha tan responden mempunyai variasi yang tinggi dari Rp 500,000 hingga Rp 45,000,000 sesuai dengan luas lahan sistem usaha tani responden. 708 responden mempunyai pengeluaran untuk sistem usaha tani (SUT) kurang dari $\mathrm{Rp} \mathrm{6.000.000.}$ Pengeluaran rumah tangga responden per bulan bervariasi dari Rp 600,000 hingga $\mathrm{Rp} \mathrm{7,500,000}$ dengan sekitar 738 responden mempunyai

pengeluaran rumah tangga per bulan kurang dari Rp 2.400 .000 . Ada 918 responden berkeinginan untuk mengembangkan SUT, dengan 98 yang tidak berkeingingan mengembangkan SUT berada di Kecamatan Taktakan karena mempunyai akses ke SUT sekarang hanya 0.2 sampai dengan $0.5 \mathrm{ha}$

\section{Gambar 5. Hasil penulisan kode dan teks}

\section{b. Teks dan tabel}

Tabel korelasi dan sidik ragam (analysis of variance) dari karakteristik responden terhadap akses usaha tani di masa depan [11] dijadikan pembahasan untuk teks dan tabel. Variabel yang akan dikorelasikan harus didefiniskan terlebih dahulu sebelum membuat tabel korelasi. Ada empat variable yang akan dikorelasikan yaitu usia, pendidikan, pengeluaran rumah tangga, dan jumlah tanggungan (jiwa). Blok kode yang dapat ditulis seperti pada Gambar 6 yang hasilnya berupa Tabel 1.

Gambar 6. Penulisan kode untuk tabel korelasi Korelasi antar variabel

\begin{tabular}{ccccc}
\hline & Usia & Pendidikan & PengeluaranRT & Jiwa \\
\hline Usia & & & & \\
Pendidikan & 0.22 & & & \\
PengeluaranRT & 0 & 0.4 & -0.03 \\
Jiwa & 0.09 & 0.1 & \\
\hline
\end{tabular}

Analisis ragam juga diterapkan pada empat variabel korelasi dengan variabel tak bebasnya adalah akses usaha tani dimasa depan. Salah satu variabel bebas yaitu pendidikan perlu dikategorikan dahulu, jika tidak maka nilai $0,1,2$, dan 3 akan dianggap nilai kontinu oleh $\mathrm{R}$. Variabel tak bebas masadepan merupakan penjumlahan dari akses usaha tani sekarang dan usaha tani yang ingin dikembangkan. Analisis sidik ragam pada artikel tersebut tidak menggunakan nilai asli dari variabel tak bebas tetapi menggunakan nilai logaritmanya, sehingga kode untuk 
tabel sidik ragam seperti pada Gambar 7 yang hasilnya berupa Tabel 2 .

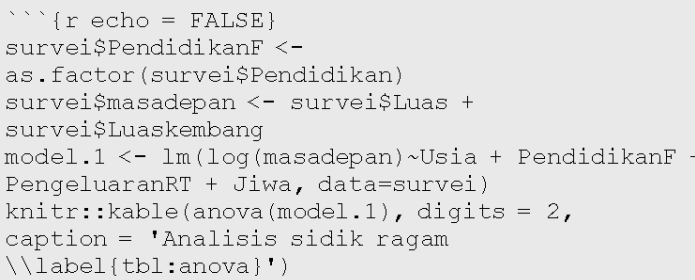

Gambar 7. Penulisan kode untuk tabel sidik ragam

Tabel 2. Analisis sidik ragam

\begin{tabular}{cccccc}
\hline & Df & Sum Sq & Mean Sq & F value & $\operatorname{Pr}(>$ F $)$ \\
\hline Usia & 1 & 0.79 & 0.79 & 1.11 & 0.30 \\
PendidikanF & 3 & 2.85 & 0.95 & 1.34 & 0.28 \\
PengeluaranRT & 1 & 3.18 & 3.18 & 4.49 & 0.04 \\
Jiwa & 1 & 1.81 & 1.81 & 2.55 & 0.12 \\
Residual & 26 & 18.43 & 0.71 & & \\
\hline
\end{tabular}

Tabel \ref $\{$ tbl:korelasi\} menunjukkan bahwa korelasi antar variabel sangat kecil, sehingga regresi linear sederhana dapat diterapkan untuk mendeteksi variabel yang berpengaruh terhadap akses ke usaha tani dimasa depan. Tabel Iref\{tbl:anova\} menunjukkan bahwa hanya variabel pengeluaran rumah tangga yang berpengaruh terhadap akses SUT dimasa depan.

\section{Gambar 8. Penulisan cross reference untuk tabel}

Tabel 1 menunjukkan bahwa korelasi antar variabel sangat kecil, sehingga regresi linear sederhana dapat diterapkan untuk mendeteksi variabel yang berpengaruh terhadap akses ke usaha tani dimasa depan. Tabel 2 menunjukkan bahwa hanya variabel pengeluaran rumah tangga yang berpengaruh terhadap akses SUT dimasa depan.

\section{Gambar 9. Hasil penulisan cross reference untuk tabel}

' $\{$ r echo $=$ FALSE, out.width='75\%', fig.cap 'Biplot indikator produksi $\backslash \backslash$ label \{gbr:biplot\}', fig.align = 'center', fig.pos = 'h' ' datala $<-$ read.table ('C:/data.txt', sep =

' , header $=\mathrm{T}$ )

datM $<-$ as.matrix (datala $[,-1]$ )

jumbar $<-$ apply (datM, 2, sum)

dataprod <- datm [,jumbar != 0]

rownames (dataprod) <- datala $[, 1]$

pca $<-$ prcomp (dataprod $[,-1]$, scale=T)

hasilpca $<-$ summary (pca)

dim $1<-$ hasilpca\$importance $[2,1] * 100$

dim2 <- hasilpcasimportance $[2,2] * 100$

biplot (pca, xlim =

$c(\min ($ as numeric (hasilpcasrotation [, 1:2])) -0.5 max (as.numeric (hasilpcasrotation [, 1:2]) ) +0.5) $\mathrm{x} l \mathrm{ab}=$ paste('Dimension 1 (', round(dim1,1),'응' ', sep $=$ ' '),

ylab = paste('Dimension 1 (', round(dim2,1),' 'o)', $s \in p=$ ')

\section{Gambar 10. Penulisan kode untuk gambar biplot}

Saat menampilkan tabel, cross reference dari tiap tabel dapat digunakan pada teks, misalnya di RStudio ditulis seperti pada Gambar 8 dan hasilnya berupa Gambar 9. Tabel-tabel yang sering digunakan untuk memperjelaskan hasil penelitian dapat dengan mudah dihasilkan dengan menggunakan Knitr::kable. Hasil analisis dengan R dapat langsung ditampilkan jika kelas (class) variabel adalah matrix atau data frame. Selain pengecekan yang mudah/minimal saat data berubah, keuntungan lain yang diperoleh adalah kemudahan pembuatan tabel tanpa harus mengubah/menyesuaikan ukuran isi/konten dari tabel. Cross reference untuk tabel juga dapat dilakukan mirip dengan cross reference pada persamaan.

\section{c. Teks dan gambar}

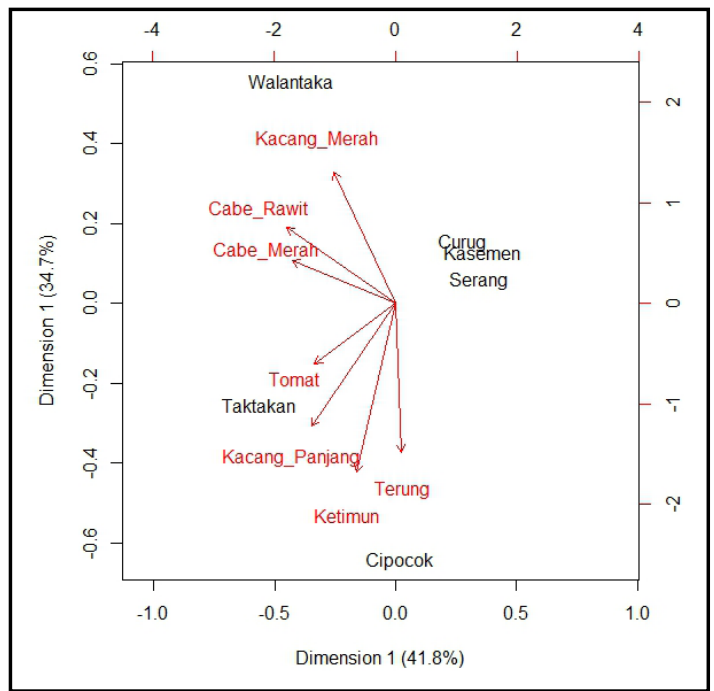

Gambar 11. Biplot

Gambar \ref\{gbr:biplot\} menunjukkan jenis komoditas yang berpotensi menjadi komoditas unggulan berdasarkan produksi komoditas di setiap kecamatan. Terung dan ketimun menjadi komoditas unggulan di Kecamatan Cipocok, tomat dan kacang panjang di Kecamatan Taktakan, cabe merah dan cabe rawit di Kecamatan Walantaka. Tiga kecamatan yaitu Kecamatan Curug, Kasemen, dan Serang belum memiliki komoditas unggulan. Keragaman total yang dapat diterangkan oleh biplot sebesar ' round (dim1+dim2,1) '`o, sehingga biplot pada Gambar \ref\{gbr:biplot\} dapat mendeskripsikan hubungan antara komoditas dan kecamatan pada dua dimensi dengan baik.

\section{Gambar 12. Penulisan cross reference untuk gambar}

Gambar 1 menunjukkan jenis komoditas yang berpotensi menjadi komoditas unggulan berdasarkan produksi komoditas di setiap kecamatan. Terung dan ketimun menjadi komoditas unggulan di Kecamatan Cipocok, tomat dan kacang panjang di Kecamatan Taktakan, cabe merah dan cabe rawit di Kecamatan Walantaka. Tiga kecamatan yaitu Kecamatan Curug, Kasemen, dan Serang belum memiliki komoditas unggulan. Keragaman total yang dapat diterangkan oleh biplot sebesar 76.5\%, sehingga biplot pada Gambar 1 dapat mendeskripsikan hubungan antara komoditas dan kecamatan pada dua dimensi dengan baik.

\section{Gambar 13. Hasil penulisan cross reference untuk} gambar

Gambar biplot (Gambar 11) dapat dihasilkan ulang untuk contoh teks dan gambar. Gambar ini adalah gambar biplot dari enam kecamatan di Kota Serang dan tujuh komoditas sayuran berdasarkan data sekunder BPS [12]. Sebelum proses pembuatan biplot, load data dari data sekunder tersebut diperlukan agar data tersimpan dalam sistem. Analisis komponen utama juga dibutuhkan untuk pembuatan biplot (Gambar 10). Perhatikan Gambar 10 menunjukkan bahwa data yang akan digunakan yaitu data. txt telah disimpan dalam folder C:/. Blok kode diantara 
dua tanda kurung kurawal $(\{\ldots\})$ terdiri atas tiga baris (lihat tiga baris pertama). Selama tidak menekan enter blok kode tersebut dapat dijalankan yang ditandai dengan highlight dilatar belakang, tetapi blok kode hanya akan dianggap teks jika latar belakangnya tidak ada hightlight (gambar biplot tidak dihasilkan). Hasil kode ini adalah biplot dua dimensi (Gambar 11).

Saat gambar ditampilkan, cross reference dari tiap gambar dapat juga digunakan pada teks seperti cross reference pada tabel. Jika di RStudio ditulis kode seperti pada Gambar 12 , hasilnya berupa paragaf yang memiliki cross reference (Gambar 13).

Seorang peneliti seharusnya mengadopsi reproducible research (data dan kode tersedia) sehingga kontribusi terhadap keilmuan lebih efektif [13] karena mendapatkan dukungan yang cukup baik dan proses yang mudah dengan R, RStudio, dan paket Knitr. Penelitian melibatkan banyak jenis data yang berbeda-beda dan banyak peneliti/ contributor memerlukan skema alur kerja secara lengkap dari pemrosesan data mentah hingga analisis [14]. Tujuannya agar data dan kode yang beragam (karena dari banyak kontributor) dapat dengan mudah disebarkan dan dipublikasikan untuk kepentingan reproducible research.

\section{Kesimpulan}

Artikel ini memberikan contoh RR dengan menggunakan RStudio, software $\mathrm{R}$ dan paket Knitr. Data dan kode yang digunakan dalam artikel ini dapat diunduh dan dijalankan ulang pada RStudio sebagai syarat standar sebuah RR. Hasil reproduksi ulang pada sebagian hasil penelitian dalam sebuah artikel dapat dilakukan dengan baik dan berhasil. Keunggulan penggunaan RStudio, software $\mathrm{R}$ dan paket Knitr yaitu teks yang dapat disisipi kode inline, cross reference yang mudah terutama pada tabel dan gambar yang sering digunakan untuk menampilkan hasil penelitian, hasil akhir berupa teks, tabel dan gambar yang dapat menyesuaikan jika terjadi perubahan data, dan peneliti lain yang ingin menggunakan kode lebih mudah sehingga RR terjamin. Peneliti yang melaporkan hasil penelitiannya seharusnya menggunakan konsep RR agar peneliti lain dapat menggunakan hasil penelitian tersebut untuk dijalankan ulang atau untuk pengembangan keilmuan lebih lanjut.

\section{Daftar Pustaka}

[1] C. Gandrud, "Reproducible Research with R and RStudio". 2nd ed. Chapman; Hall, 2015.

[2] G. King, R. Keohane, and S, Verba. Designing
Social Inquiry. Princeton University Press, 1994.

[3] V. Stodden, J. Seiler, and Z. Ma, "An Empirical Analysis of Journal Policy Effectiveness for Computational Reproducibility". Proceedings of the National Academy of Sciences 115 (11). National Academy of Sciences: 2584-2589, 2018.

[4] Peng, R. D, "Reproducible Research in Computational Science". Science, 1226-1227. 2011.

[5] Stodden, V., Leisch F., and R. D Peng, "Implementing Reproducible Research". Chapman; Hall, 2014.

[6] Leisch, F, "Sweave: Dynamic Generation of Statistical Reports Using Literate Data Analysis". In Proceedings in Computational Statistics, edited by W. Härdle and B. Rönz, 575-580. Physika Verlag, Heidelberg, Germany, 2002.

[7] Yihui, X, "Dynamic Documents with R and Knitr”. Chapman; Hall, 2015.

[8] Biecek, P., and M. Kosinski, "Archivist: An R Package for Managing, Recording and Restoring Data Analysis Results". Journal of Statistical Software 82, 2017.

[9] R Core Team. R, "A Language and Environment for Statistical Computing". Vienna, Austria: R Foundation for Statistical Computing. https:// www.R-project.org/, 2015.

[10] Yihui, X, Knitr: A General-Purpose Package for Dynamic Report Generation in R. 2017.

[11] W. Budiaji, J. Pancawati, and Suherna. "Vegetables Mapping Using Production and Socioeconomic Indicators Approach". In ICoSI 2014 Proceedings of the 2nd International Conference on Sustainable Innovation, edited by Taufik T. et al., 109-118. Springer, Singapore, 2017.

[12] BPS. Kota Serang Dalam Angka 2011. Badan Pusat Statistik Kota Serang, 2012.

[13] Ivie, P., and D. Thain, "Reproducibility in Scientific Computing." ACM Computing Surveys 51 (3). New York, NY, USA: ACM: 63:1-63:36, 2018.

[14] Finak, G., B. Mayer, W. Fulp, P. Obrecht, A. Sato, E. Chung, D. Holman, and R. Gottardo. "DataPackageR: Reproducible Data Preprocessing, Standardization and Sharing Using R/Bioconductor for Collaborative Data Analysis [Version 2; Referees: 2 Approved, 1 Approved with Reservations]." Gates Open Research 2 (31), 2018. 